\title{
20. Culture
}

\section{Nicolas Peterson}

It was unclear in the original 1994 NATSIS survey what the purpose and significance of the 'Culture' questions were: in some respects this still remains true for the 2002 survey. A number of possible reasons for collecting cultural data were canvassed in the assessment of the previous survey. These included the need to recognise regional cultural variation, to help in designing culturally appropriate policies, to assist in formulating policies on cultural maintenance, and to help in identifying cultural issues or practices that may stand in the way of the achievement of policy goals.

Some insight into the thinking relating to the cultural questions can be gained from the planning of the original survey, when an early step was to identify nine topic headings under which information would be sought. Culture was one of these, and under this topic 'location and mobility' were proposed as important, as were matters relating to family. This suggests that culture was seen as referring to those aspects of mobility and family that differ substantially among Indigenous people from the rest of the population. As it turned out, the request for certain information about mobility was dropped because the pilot survey found the recall data on this topic too unreliable. It may well be the case that it was generally felt that gaining cultural data that would contribute significantly to policy formation was seen as too complex for such a long questionnaire, and that the real concern with culture was more bureaucratic. That is, that the interest was really to obtain data 'to broadly evaluate specific agency programs first, and broad policy second, and a generally-held view that some data are better than none' (Altman \& Taylor 1996: 200). Indeed, a conclusion of the previous assessment was that the interest in culture was primarily to do with cultural maintenance (Peterson 1996: 151), referred to by the ABS as 'cultural retention' (2004c: 2).

In this light, it is interesting to consider whether the nature of the 'culture' questions in the 2002 survey reflect this. While the principal culture questions fall within the 'Culture' section of the CAI questionnaire, there are a few other 'culture' questions elsewhere in the survey.

The first four questions in the culture section of the CAI questionnaire are grouped under the heading 'language'. Two of these are about languages spoken and two about whether the interviewee has difficulty being understood in service delivery situations. These are quintessentially culture questions and - in tandem with the 1994 survey - allow for some estimate of the maintenance of Aboriginal languages and for policy recommendations in respect of service delivery, from 
education to employment. The results of this part of the survey are discussed separately by Frances Morphy and Inge Kral in the next chapter.

The next seven questions, which deal with 'cultural participation/involvement in social activities' are divided into two parts. For these and all of the questions where it made sense, people could choose more than one response. The 'cultural activities' a person participates in are defined as: funerals, ceremonies, sports carnivals, 'festivals or carnivals involving arts, craft, music or dance', and being 'involved with any Aboriginal or Torres Strait Islander organisations'? (CAI Questionnaire: p.55). The first question in relation to these asks whether people had been involved in any or none of these; the second asks whether the person had done any of the following, including as part of their job: made any arts or crafts, performed any music, dance or theatre or written or told any stories. The third question was whether they had been paid for any of these activities and the fourth asks which of the activities they had been paid for. These all provide interesting information about what people are actually doing, although the way that the results are presented in ABS (2004c) is not particularly helpful. There, funerals and ceremonies are collapsed with sports carnivals and the rest, which means events that, it can be assumed, Aboriginal people get themselves to unaided, are lumped in with festivals and events that are subsidised and organised by State agencies and committees, etc. The former are an index of independent cultural retention, versus the latter which are, of course, cultural, in the sense that they are what people are doing as part of their everyday lives now, but more a measure of what might be called contemporary state-aided social capital.

The next three questions were about kinds of involvement with sport in the last 12 months, with the possibilities being: as player or participant, as coach, instructor or teacher, as referee, umpire or official, as committee member or administrator, or other. The third question asks whether, in the last three months, the person has participated in any of the following activities: recreational group or cultural group activities; community or special interest group activities; church or religious activities; went out to a café, restaurant or bar; took part in sport or physical activities; attended sporting event as a spectator; visited library, museum or art gallery; attended movies, theatre or concert; visited park, botanic gardens, zoo or theme park; or none of these. Rather than being concerned with cultural retention, the focus of these questions seems to be on establishing some of the things people do with their non-work time. While the possibilities offered in respect of sport make good sense, the range of possibilities referred to in the third question do not all seem to be of equal significance, nor the relevance of some, clear. Church attendance does seem important, not least because it is frequently associated, in theory, with a limitation on certain kinds of activity, but mixing café attendance with going to a bar does not seem helpful. As to the 
list of mainstream cultural activities, the purpose of the questions is again unclear and their possible policy implications obscure.

The next four questions are grouped under the heading 'cultural identification' and include whether the person identifies with a tribal group, a language group, or a clan; whether they recognise a homeland or traditional country and whether they are currently living there; and, finally, whether they are allowed to live there. The identity questions are significant given native title and the changes taking place in the census. Those relating to homelands are, however, ambiguous, since one usage of this term is as an equivalent of outstation, whereas the usage here appears to relate to living on Aboriginal land to which one feels one has a right. Clarifying this distinction would be helpful.

The last three questions on the CAI questionnaire, for which permission was first asked to talk about the subject, are under the heading 'removal from family'. The person is asked whether they were taken from their natural family by a mission, the government or welfare; whether any of their relatives were taken away by the same groups; and which of their relatives were taken away from their natural families. Seven classes of close relative are named, and there are three alternatives of 'other', 'don't know', and 'don't want to answer'. The purpose of these questions and their usefulness in cross-correlating with other issues has been well demonstrated (Borland \& Hunter 2000; Hunter 2001).

\section{Changes to survey questions}

A considerable number of changes have been made to the questions asked under the section 'Culture'. In respect of the 'Language module' (CAI Questionnaire: p.54), the questions are similar but better phrased. In respect of the 'Cultural participation/involvement in social activities' module (CAI Questionnaire: p.55), the first question is changed by the inclusion of a distinct category for 'Sports carnival'. In 1994 the list of activities was followed by a question about whether and what obstacles prevented people from going to the various activities, with six possibilities and 'Other' listed. The equivalent question is now found in a shortened form in the 'Transport' module (CAI Questionnaire: p.31). The 1994 question about a place to meet for cultural activities has been dropped. In its place are a whole set of new questions about making craft, cultural performance, and whether people were paid for them; about sport and the role taken in it (CAI Questionnaire: p.56-Q02IISA), and about social activities (CAI Questionnaire: p.57-Q03IISA). The questions under the 'Cultural identification' module (CAI Questionnaire: p.58) have been considerably simplified, especially in relation to homelands/traditional country. Now there are just three questions, in place of ten. The question in the 1994 survey on elders has also been removed. Finally, the questions in the 'Removal from family' module (CAI Questionnaire: p.59) have been slightly changed: the initial question remains the same but in place 
of asking about who brought the removed person up, two questions are asked about whether other close relatives were removed.

Overall, the changes are an improvement. They provide more information on the actual social and sporting activities people undertake, and wasted questions (such as those on elders, on the obstacles to people going to activities and the questions about a place for cultural activities) have been removed. In respect of the various kinds of activities asked about, it seems that better questions could be found to replace those related to libraries, theatres and zoos.

\section{Findings on cultural participation/involvement in social activities}

A comparison of the findings between 1994 and 2002 is the principal way in which to give the figures some meaning (see Table 20.1). Broadly speaking, there is little overall change. Despite a small decline in the numbers participating in funerals, attendance at funerals remains at a very high level. An increase in the participation in ceremonies could be seen as heartening, if it is true, but it seems counter-intuitive. On the other hand, the increase in participation in festivals and carnivals, which include sport, seems entirely plausible.

Table 20.1. Cultural participation/ involvement in social activities in 1994 and $2002^{\mathrm{a}}$

\begin{tabular}{lrr}
\hline & 1994 & $\mathbf{2 0 0 2}$ \\
& $\%$ & $\%$ \\
\hline Funerals & 53.2 & 46.6 \\
Ceremonies & 19.3 & 23.5 \\
Festivals/carnivals involving arts, craft, music, dance \& sport & 41.7 & 45.9 \\
Been involved with any ATSI organisation & 23.7 & 26.1 \\
\hline
\end{tabular}

a. The 1994 figures use the original weights on a population of 13 plus, while the 2002 tables are for a population of 15 plus. For the purposes of this chapter, it is assumed that this difference can be ignored, as it will not substantively affect the distributions.

Source: ABS (2004c: 31)

It would be interesting to divide these figures between remote and non-remote for both periods but that has not been possible to date. However, for 2002 that division has been supplied (see Table 20.2). The differences are marked in respect of funerals, ceremonies and sports carnivals, broadly involving more than double the percentage of people in remote Australia. Interestingly, the proportion of people involved with ATSI organisations is virtually the same, indicating how relations with government are a central part of contemporary Aboriginal life everywhere. 
Table 20.2. Cultural participation/involvement in social activities by remoteness, 2002

\begin{tabular}{lrrr}
\hline & Remote & Non-remote & Australia total \\
& $\%$ & $\%$ & $\%$ \\
\hline Funerals & 74.1 & 36.3 & 46.6 \\
Ceremonies & 45.0 & 15.5 & 23.5 \\
Sports carnivals & 52.8 & 21.2 & 29.8 \\
Festival/carnival involving arts, craft, music or dance & 41.7 & 33.5 & 35.7 \\
Involved with ATSI organisations & 24.9 & 26.5 & 26.1 \\
\hline
\end{tabular}

Source: ABS (2004c: 38)

If the survey is going to be useful in measuring cultural retention through the participation in cultural and social activities, it is important these categories are not changed again.

Table 20.3. Paid and unpaid participation in cultural activities, 2002

\begin{tabular}{lrr}
\hline & Paid & Unpaid \\
\hline Arts and crafts & 13993 & 31672 \\
Dance or theatre & 7510 & 15958 \\
Writing or telling stories & 7670 & 27773 \\
Cultural activities & 21703 & 55620 \\
\hline
\end{tabular}

Source: Customised cross-tabulations from the 2002 NATSISS CURF

The 1994 survey failed to ask anything about the arts and crafts industry, so it would seem that the new questions about paid and unpaid participation in cultural activities are to fill that gap (see Table 20.3). It is not clear, however, what to make of the numbers in the unpaid column. Nor is it clear what to make of the commodification of these activities. Art and craft is, one can assume, production for sale and rather different from the 'dance and theatre' category, and the 'writing or telling stories' which presumably relate to the subsidising of public performances, teaching in schools and the like. The last category is not at all helpful, as it is too generalised. But if it means that cultural activities such as funerals and ceremonies are being subsidised, then it could be a concern, because it would indicate bureaucratic intrusion into areas of personal, social and cultural life which people should be able to sustain themselves. If they are unable to do so, it has to be asked what role and purpose the state has in trying to maintain these practices on Aboriginal people's behalf.

Table 20.4. Participation in sporting activity by remoteness, 2002

\begin{tabular}{lrrrr}
\hline & Remote & Non-remote & $\begin{array}{r}\text { Australia total } \\
\text { Australia total } \\
\text { (number) }\end{array}$ \\
\hline Player or participant & $\%$ & $\%$ & $\%$ & \\
Coach instructor or teacher & 49.2 & 44.8 & 46.0 & 129864 \\
Referee, umpire or official & 10.1 & 7.5 & 8.2 & 23240 \\
Committee member or administrator & 9.4 & 5.0 & 6.2 & 17559 \\
Other & 12.3 & 3.2 & 5.7 & 16089 \\
\hline
\end{tabular}

Source: ABS (2004c: 38) 
The detail provided on participation in sport is good, and overtime will provide a measure of the significance of this category of activity in Aboriginal life (see Table 20.4). At present, sport is enormously important, with nearly half the population claiming to be actively involved and over half involved as a spectator.

Table 20.5 shows that data for other activities in the last three months include the nebulous and unhelpful category of 'Went out to a café, restaurant or bar', which lumps alcohol consumption with eating and coffee drinking. What is needed to improve the social and policy significance of the information on participation in sport is the addition of some measure of intensity.

There are some important differences in remote/non-remote participation, particularly in respect of church or religious activities, with 40.7 per cent of remote people participating in such activities while only 17.3 per cent of non-remote people do so.

Table 20.5. Activities participated in during the three months before the 2002 NATSISS

\begin{tabular}{lr}
\hline & Australia total \\
& $\%$ \\
\hline Recreational group or cultural group activities & 27.7 \\
Community or special interest group activities & 19.5 \\
Church or religious activities & 23.7 \\
Went out to a café, restaurant or bar & 57.1 \\
Took part in sport or physical activities & 37.8 \\
Attended sporting event as a spectator & 48.1 \\
Visited library, museum or art gallery & 23.1 \\
Attended movies, theatre or concert & 32.6 \\
Visited park, botanic gardens, zoo or theme park & 32.7 \\
Fishing or hunting in a group & 13.9 \\
Not involved in social activities & 10.0 \\
\hline
\end{tabular}

Source: ABS (2004c: 38) and customised cross-tabulations from the 2002 NATSISS CURF

\section{Cultural identification}

The question of identification with a tribal group, language group or clan produced a surprising result (see Table 20.6). The 1994 NATSIS was right at the beginning of the impact of native title. I predicted that with the impact of native title claims, this kind of cultural identification would grow because, particularly in settled Australia, native title claims are usually built around such identifications, and claims are filed in the name of such groups (Peterson 1996). However, remarkably, there has been a decline of around four percentage points between 1994 and 2002 in the propensity to identify with a tribal group. This may mean that by 2002, native title no longer gripped the imagination of many Aboriginal people. 
Table 20.6. Identification with a tribal group, a language group or a clan 2002

\begin{tabular}{lrr}
\hline & Number & Per cent \\
\hline Yes & 152806 & 54.1 \\
No & 123340 & 43.7 \\
Don't know & 6058 & 2.1 \\
\hline
\end{tabular}

Source: Customised cross-tabulations from the 2002 NATSISS CURF

The most interesting figure in respect of homelands (an ambiguous term) is the number of people who do not identify with a homeland, which is up by 5 per cent from the 1994 Census. If this is correct, it is perhaps an indirect measure, of some kind, of the population of Aboriginal descent that is integrated into the wider society, and linked to the changes in identification so marked in the census. It is not surprising, however, that only 21.9 per cent of people live on their own homeland, since just under one-third of the population lives in cities and over two-thirds in settled Australia (see Table 20.7). Since 1994, there has been a decline in about 7 per cent of the population living on their own homeland, a fact which probably reflects real changes going on across the continent.

Table 20.7. Relations with homeland/traditional country, by remoteness in 2002

\begin{tabular}{lrrr}
\hline & Remote & Non-remote & $\begin{array}{r}\text { Australia total } \\
\%\end{array}$ \\
\hline Recognises homelands/traditional country & $\%$ & 63.4 & 69.6 \\
Does not recognise homelands/traditional country & 85.8 & 36.6 & 30.4 \\
Living there now & 14.2 & 15.8 & 21.9 \\
Not allowed to visit traditional country & 38.0 & 0.5 & 0.5 \\
\hline
\end{tabular}

Source: ABS (2004c: Table 12)

The decline in people denied visiting access to their country from 49 per cent of remote Indigenous people to virtually zero is remarkable, and suggests that either the original 1994 figure or this figure is wrong.

\section{Cultural and family responsibilities}

References to 'family responsibilities or considerations' are found at two points through the 2002 NATSISS questionnaire for non-remote areas (CAI Questionnaire: pp.20, 24). They appear in relation to why people finished school: '20-Other personal/family reasons', or why they are not looking for work (CAI Questionnaire: p.24). More specifically, they appear in the 'Cultural responsibilities' module (CAI Questionnaire: p.20). Here, cultural responsibilities are defined as including, 'such things as telling traditional stories, being involved in ceremonies and attending events such as funerals or festivals'. The question asked was: 'Because you work, is it possible to meet all your cultural responsibilities?'. Pressure to fulfill cultural responsibilities is also listed as a possible source of problems (stresses) for the interviewee or their family and friends (CAI Questionnaire: p.49). The definition of 'cultural responsibilities' 
used is problematic because it includes both voluntary and involuntary responsibilities. Telling traditional stories or attending festivals would usually be rather more optional than attending a funeral for a close relative.

\section{Conclusion}

The figures relating to the declining proportion of respondents with a tribal/clan affiliation and to those identifying with a homeland, raise the question of the extent to which the NATSIS results are affected by the recent dramatic increases in the proportion of people self-identifying as Indigenous. It seems likely that this may be having the effect of adding to that section of the Indigenous population who are closest in their characteristics to the general population. If this is correct, it is surprising because one might expect that one of the reasons for the recent increase in self-identification was that people were seeking to be included in native title claims and, therefore, likely to take on a tribal/clan identification and/or identify with a homeland as part of that. The fact that this does not seem to be the case suggests that those commentators who have argued that the motivation of many who recently self-identify as Indigenous is to take advantage of the alleged material benefits of being Indigenous are wrong, and this underlines the complexity of the identity issues.

The questions in the 2002 survey are, overall, a considerable improvement over those included in 1994. They are more detailed and specific and a number of wasted questions have been removed. Nevertheless, there is an opportunity to improve the questions further and to introduce other questions. In particular, more care needs to be given to separating different kinds of activity, such as those that are organised independently of the state from those that are subsidised, and those which are basically optional from those which are not.

Since 1994 the difficult issue of the role of 'culture' in sometimes aggravating some of the social problems people have been facing has been cautiously opened up for public debate (Atkinson 1990; Brady 2004; Martin 1993; Pearson 2001; Peterson 1999: 856-59; Sutton 2001). The sort of cultural issues addressed in this literature are not, however, easily examined by survey, since they relate to issues such as aspects of sharing practices, child rearing, and ways of relating, which may have implications for areas such as health, domestic violence and material wellbeing. While such matters may not be easily addressed directly by survey, the possibility exists that there may be proxy ways in which these matters can be approached. However, this again may be difficult, and even if correlations were to be shown between the proxy and particular negative outcomes, the policy implications and consequences might be obscure. There are, however, other questions that could be usefully asked from a policy point of view. 
In the previous commentary on the 1994 survey (Peterson 1996) it was suggested that the technique adopted by Moisseeff (1994) in her interesting community survey of Port Augusta could be applied here. It would help researchers learn about important issues such as people's priorities, provided the results could be abstracted at a community level. She asked people about their main priorities for the community, offering them 12 possibilities which, apart from providing concrete evidence of people's priorities, produced interesting differences between the weight and ranking given to priorities between men and women. Further, rather than assuming what is significant in terms of cultural maintenance, such as attending ceremonies etc, it would be better to let the interviewees nominate what they see as important in this respect. It would be of greater policy significance if the survey questions were more specific, focusing on information needs and facilities that directly affect people's daily life.

In a more extended analysis, it would be important to cross-tabulate a number of the results from the culture questions with other sections of the survey. Thus, for example, it would be interesting to see if sports participation, living on homelands or church attendance correlates with measures of community wellbeing, age and gender, as might be expected. Some direct policy implication could flow from any such positive correlations. 